\title{
Temperature Model in Support of the U.S. Geological Survey National Crustal Model for Seismic Hazard Studies
}

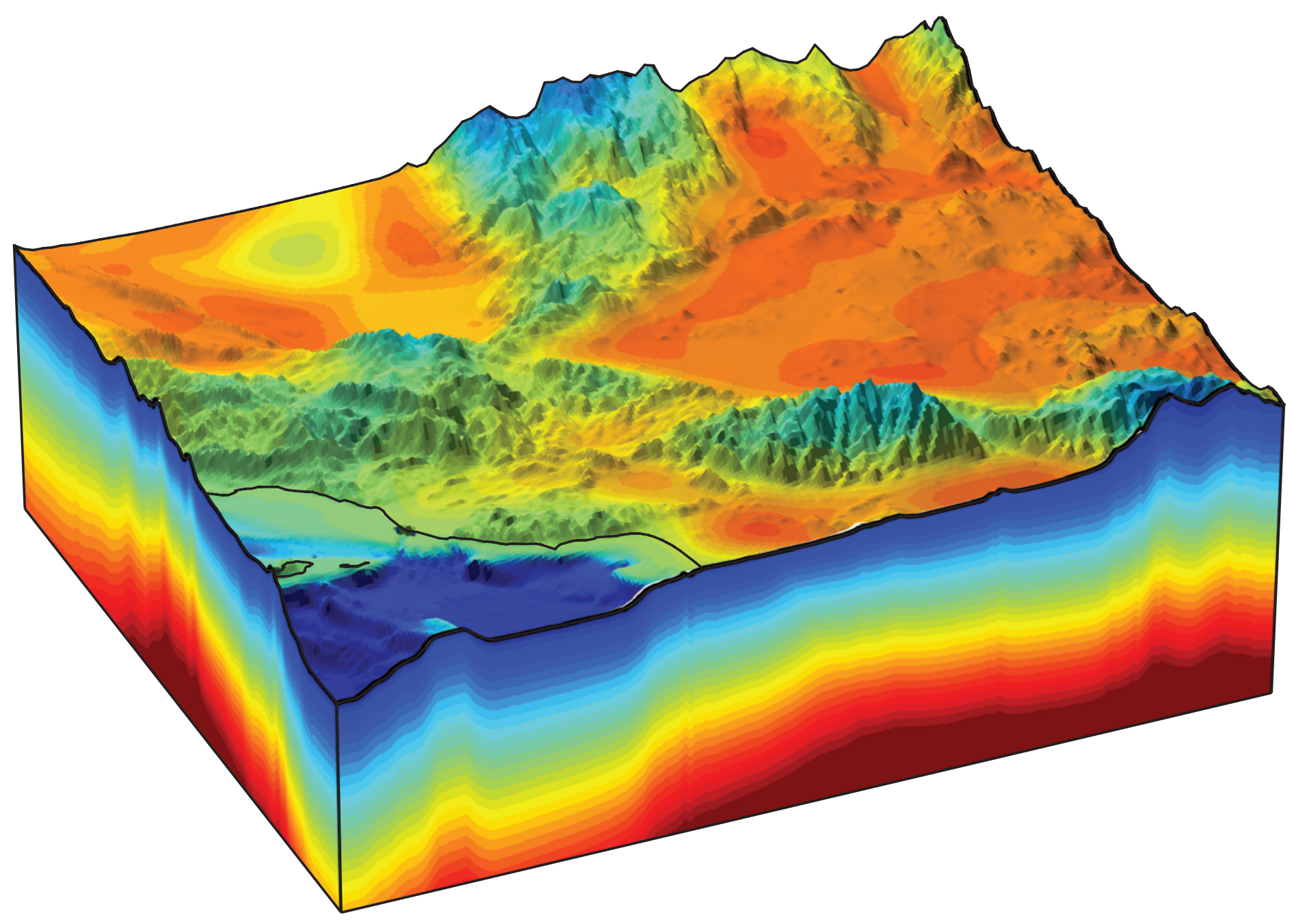

Open-File Report 2019-1121 
Cover. Temperature cross sections through the thermal model in southern California. Average surface temperatures vary between about 0 and 30 degrees Celsius, whereas the vertical profiles extend to 10 kilometers below sea level and vary between 0 and 300 degrees Celsius. 


\section{Temperature Model in Support of the U.S. Geological Survey National Crustal Model for Seismic Hazard Studies}

By Oliver S. Boyd

Open-File Report 2019-1121 


\title{
U.S. Department of the Interior DAVID BERNHARDT, Secretary
}

\author{
U.S. Geological Survey \\ James F. Reilly II, Director
}

\section{U.S. Geological Survey, Reston, Virginia: 2020}

For more information on the USGS - the Federal source for science about the Earth, its natural and living resources, natural hazards, and the environment-visit https://www.usgs.gov or call 1-888-ASK-USGS.

For an overview of USGS information products, including maps, imagery, and publications, visit https://store.usgs.gov.

Any use of trade, firm, or product names is for descriptive purposes only and does not imply endorsement by the U.S. Government.

Although this information product, for the most part, is in the public domain, it also may contain copyrighted materials as noted in the text. Permission to reproduce copyrighted items must be secured from the copyright owner.

Suggested citation:

Boyd, O.S., 2020, Temperature model in support of the U.S. Geological Survey National Crustal Model for seismic hazard studies: U.S. Geological Survey Open-File Report 2019-1121, 15 p.,

https://doi.org/10.3133/ofr20191121.

Associated data for this publication:

Boyd, 0.S., 2019, Grids in support of the U.S. Geological Survey thermal model for seismic hazard studies: U.S. Geological Survey data release, https://doi.org/10.5066/P935DT1G.

ISSN 2331-1258 (online) 


\section{Contents}

Abstract

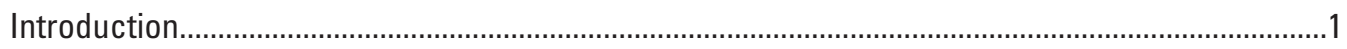

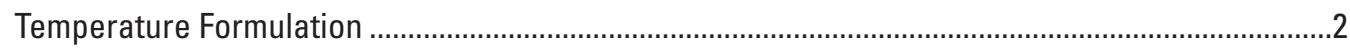

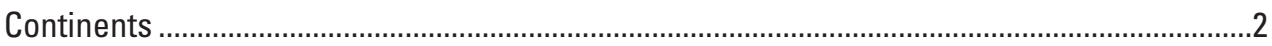

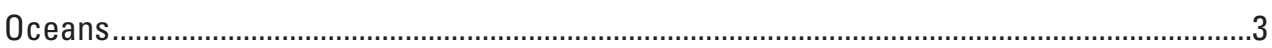

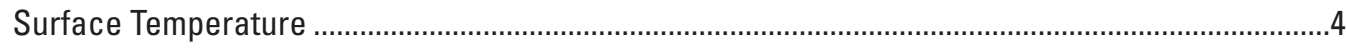

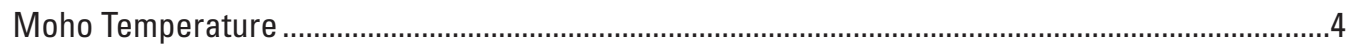

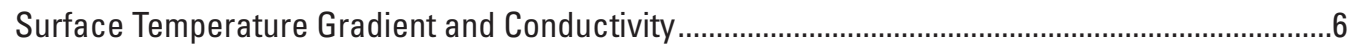

Deep Crustal Conductivity .....................................................................................................

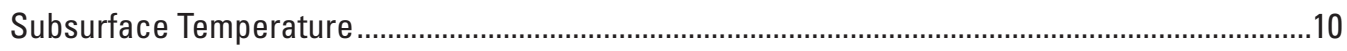

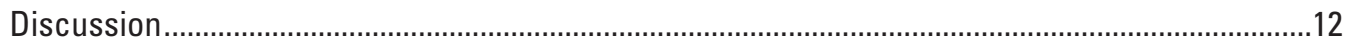

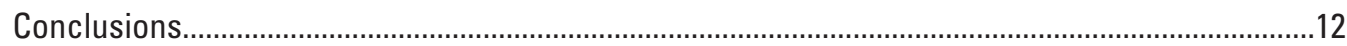

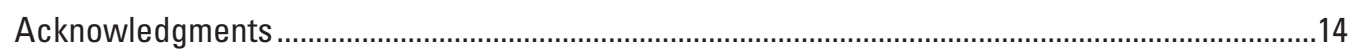

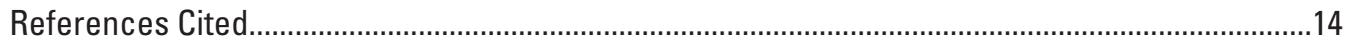

\section{Figures}

1. Map of present-day surface temperature in the United States and part of North America. Temperatures are generally lower at higher altitudes, higher latitudes, and at greater ocean depths.............................................................................

2. Graph of the bilinear relationship between $\mathrm{P}$-wave $(\mathrm{Pn})$ velocity and Pn-based Moho temperature estimates....

3. Maps of Moho temperature in degrees Celsius $\left({ }^{\circ} \mathrm{C}\right)$ in the United States and part of North America.

4. Maps of locations of observed surficial temperature values in the United States and part of North America. Along the top panels. $A$, Measured corrected borehole temperature gradients; $B$, conductivity; and $C$, heat production, $H_{S^{1}} 14$...

5. Graph of the comparison between observed and predicted Moho temperature for constant thermal conductivity at each of the 88,762 locations where a temperature gradient is observed in the Southern Methodist University Geothermal Laboratory data set (SMU, 2015)...

6. Maps of temperature slices within the U.S. Geological Survey National Crustal Model domain at $3.5(B), 10(C)$, and $30(D)$ kilometers $(\mathrm{km})$ depth as well as the temperature at $3.5 \mathrm{~km}$ depth from the Southern Methodist Geothermal Laboratory (SMU, 2015) model $(A)$

7. Graph of one-dimensional temperature profiles at four locations across the United States with locations indicated in figure $6 \mathrm{~s}$.....

8. Cross section of a temperature profile through the Cascadia subduction zone in Washington, Idaho, and part of Montana. 


\section{Conversion Factors}

International System of Units to U.S. customary units

\begin{tabular}{lll}
\hline \multicolumn{1}{c}{ Multiply } & By & \multicolumn{1}{c}{ To obtain } \\
\hline & Length & \\
\hline meter $(\mathrm{m})$ & 3.281 & foot $(\mathrm{ft})$ \\
kilometer $(\mathrm{km})$ & 0.6214 & mile $(\mathrm{mi})$ \\
kilometer $(\mathrm{km})$ & 0.5400 & mile, nautical $(\mathrm{nmi})$ \\
meter $(\mathrm{m})$ & 1.094 & yard $(\mathrm{yd})$ \\
\hline & Density & \\
\hline gram per cubic centimeter $\left(\mathrm{g} / \mathrm{cm}^{3}\right)$ & 62.4220 & pound per cubic foot $\left(\mathrm{lb} / \mathrm{ft}^{3}\right)$ \\
\hline
\end{tabular}

Temperature in degrees Kelvin (K) may be converted to degrees Celsius $\left({ }^{\circ} \mathrm{C}\right)$ as follows:

$$
{ }^{\circ} \mathrm{C}=\mathrm{K}-273.15
$$

Temperature in degrees Celsius $\left({ }^{\circ} \mathrm{C}\right)$ may be converted to degrees Fahrenheit $\left({ }^{\circ} \mathrm{F}\right)$ as follows:

$$
{ }^{\circ} \mathrm{F}=\left(1.8 \times{ }^{\circ} \mathrm{C}\right)+32 .
$$

Temperature in degrees Fahrenheit $\left({ }^{\circ} \mathrm{F}\right)$ may be converted to degrees Celsius $\left({ }^{\circ} \mathrm{C}\right)$ as follows:

$$
{ }^{\circ} \mathrm{C}=\left({ }^{\circ} \mathrm{F}-32\right) / 1.8 \text {. }
$$

\section{Datum}

Vertical coordinate information is referenced to the World Geodetic System 1984 (WGS84).

Horizontal coordinate information is referenced to the North American Datum of 1983 (NAD 83).

Altitude, as used in this report, refers to distance above the vertical datum.

\section{Abbreviations}

CEUS Central and eastern United States

NCM National Crustal Model

USGS U.S. Geological Survey

WUS Western United States 


\title{
Temperature Model in Support of the U.S. Geological Survey National Crustal Model for Seismic Hazard Studies
}

\author{
By Oliver S. Boyd
}

\begin{abstract}
The U.S. Geological Survey National Crustal Model (NCM) is being developed to assist with earthquake hazard and risk assessment by supporting estimates of ground shaking in response to an earthquake. The period-dependent intensity and duration of shaking depend upon the three-dimensional seismic velocity, seismic attenuation, and density distribution of a region, which in turn is governed to a large degree by geology and how that geology behaves under varying temperatures and pressures.

A three-dimensional temperature model is presented here to support the estimation of physical parameters within the U.S. Geological Survey NCM. The crustal model is defined by a geological framework consisting of various lithologies with distinct mineral compositions. A temperature model is needed to calculate mineral density and bulk and shear modulus as a function of position within the crust. These properties control seismic velocity and impedance, which are needed to accurately estimate earthquake travel times and seismic amplitudes in earthquake hazard analyses. The temperature model is constrained by observations of surface temperature, temperature gradient, and conductivity, inferred Moho temperature and depth, and assumed conductivity at the base of the crust. The continental plate is assumed to have heat production that decreases exponentially with depth and thermal conductivity that exponentially changes from a surface value to 3.6 watts per meter-Kelvin at the Moho. The oceanic plate cools as a half-space with a geotherm dependent on plate age. Under these conditions, and the application of observed surface heat production, predicted Moho temperatures match Moho temperatures inferred from seismic P-wave velocities, on average. As has been noted in previous studies, high crustal temperatures are found in the western United States, particularly beneath areas of recent volcanism. In the central and eastern United States, elevated temperatures are found from southeast Texas, into the Mississippi Embayment, and up through Wisconsin. A USGS ScienceBase data release that supports this report is available and consists of grids covering the NCM across the conterminous United States, for example, surface temperature and temperature gradient, that are needed to produce temperature profiles.
\end{abstract}

\section{Introduction}

The U.S. Geological Survey (USGS) National Crustal Model (NCM) is being developed to assist with earthquake hazard and risk assessment by supporting estimates of ground shaking in response to an earthquake (Boyd and Shah, 2018). The perioddependent intensity and duration of shaking depend upon the three-dimensional (3D) seismic velocity, seismic attenuation, and density distribution of a region, which in turn is governed to a large degree by geology and how that geology behaves under varying temperatures and pressures.

Increasing pressure closes pore space, thereby reducing porosity, and compresses mineral grains. Both effects increase density and seismic velocities. Pressure increases with depth at a relatively steady rate nearly independent of latitude and longitude. Temperature, on the other hand, which also increases with depth, decreases density and seismic velocities. But temperature is also more highly variable laterally (Blackwell and others, 2011) with temperatures at a given depth being hotter in the western United States (WUS), particularly in the Basin and Range Province, than they are in the central and eastern United States (CEUS) far from plate boundaries and active tectonics.

The significant lateral variability in temperature can lead to strong variations in geophysical properties (Sowers and Boyd, 2019), both due to the temperature dependence of any given mineral, and in particular, the phase transition from $\alpha$ to $\beta$ quartz, which decreases in depth with increasing temperature (Shen and others, 1993). Rather than assume a constant gradient, this variability can be considered by building a 3D temperature model using a trove of available data. 
In this report, a 3D temperature model is presented, built with a variety of published sources as detailed in subsequent sections. The model spans the bounds of the NCM from the surface to below the Moho and is based on surface temperature, Moho temperature and depth, the top and age of the oceanic plate, and borehole observations of near-surface temperature gradient and crustal heat production and conductivity. These quantities are combined in standard heat flow equations for continental and oceanic geotherms. A USGS ScienceBase data release that supports this report is available at https://doi.org/10.5066/P935DT1G (Boyd, 2019a). The data release consists of grids covering the NCM across the conterminous United States, for example, surface temperature and temperature gradient, that are needed to produce temperature profiles using the equations presented in the following sections. Software is available at https://code.usgs.gov/ghsc/nshmp/ncm/thermod to facilitate these calculations.

\section{Temperature Formulation}

\section{Continents}

Following the treatment of heat transfer in chapter 4 of Turcotte and Schubert (1982) for Fourier's Law of heat conduction with heat production, the differential equation,

$$
0=k(z) \frac{d^{2} T}{d z^{2}}+\frac{d k}{d z} \frac{d T}{d z}+\rho H(z)
$$

where

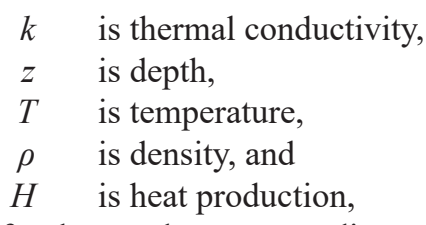

is solved for the steady state one-dimensional (1D) temperature profile in the crust under the following constraints: the temperature at the Earth's surface is $T_{S}$; the surface temperature gradient is $d T / d z_{S}$; the temperature at the Moho is $T_{M}$; the depth to the Moho is $d_{M}$; the heat production per unit mass decays exponentially with depth from a surface value to 1/e at a depth of $h_{r}$; the conductivity exponentially changes from a surface value, $k_{S}$, to a Moho value, $k_{M}$; and density is constant. Under these conditions, the temperature, $T$, as a function of depth, $z$, can be formulated to be independent of surface heat production and density and given by

$$
T(z)=\frac{c_{1} z+c_{2}-c_{3} H_{r}^{2} e^{\frac{-z}{H_{r}}}}{1+\frac{z}{k_{r}}}
$$

where

$$
\begin{gathered}
c_{1}=\frac{d T}{d z_{S}}+\frac{T_{S}}{k_{r}}-c_{3} H_{r} \\
c_{2}=T_{s}+c_{3} H_{r}^{2} \\
c_{3}=\frac{T_{M}\left(1+\frac{d_{M}}{k_{r}}\right)-d_{M} \frac{d T}{d z_{S}}-T_{S}\left(1+\frac{d_{M}}{k_{r}}\right)}{H_{r}^{2}-H_{r} d_{M}-H_{r}^{2} e^{\frac{-d_{M}}{H_{r}}}}
\end{gathered}
$$




$$
H_{r}=\left(\frac{1}{h_{r}}+\frac{1}{k_{r}}\right)^{-1}
$$

and

$$
k_{r}=\frac{d_{M}}{\ln \left(\frac{k_{m}}{k_{s}}\right)} .
$$

The depth, $h_{r}$, over which heat production decays to 1/e is assumed to be 30 percent of the depth to the Moho, which is the average for several observations in the United States (Čermák and Bodri, 1992).

This formulation is steady state and assumes that surface temperature has been held constant. However, surface temperatures over the last 10 thousand years (ka) have been about 5 degrees warmer than the average over the last $\sim 1$ million years (Ma) (Jouzel and others, 2007). A small perturbation is therefore added to this equation equal to:

$$
\Delta T(z)=5 e^{\frac{-z}{h_{T}}}
$$

where the characteristic length scale,

$$
h_{T}=\sqrt{\frac{\kappa t}{\pi}}
$$

is a function of thermal diffusivity, $\kappa$, set equal to $1 \times 10^{-6}$ meters squared per second $\left(\mathrm{m}^{2} / \mathrm{s}\right)$, and the time, $t$, over which the perturbation has been active.

Beneath the Moho, the depth of which is taken from Boyd (2019b) based on the work of Buehler and Shearer (2017) and Pasyanos and others (2014), the conductivity increases to 4.5 watts per meter-Kelvin (W/m-K) (Stacey, 1992), which decreases the temperature gradient by 20 percent. Temperatures continue to increase along a conductive geotherm until they reach an upper mantle adiabat. At this point, the temperature gradient transitions to a value of 0.4 degrees Celsius per kilometer $\left({ }^{\circ} \mathrm{C} / \mathrm{km}\right)$ until it hits the top of the mantle transition zone at $410 \mathrm{~km}$ depth and a temperature of $1,579{ }^{\circ} \mathrm{C}$ (Stacey, 1992); though this could be refined in future versions of the model using the results of Kaban and others (2014).

Within the crust and uppermost mantle, high temperatures are limited by a basalt solidus curve given by $1,100{ }^{\circ} \mathrm{C}+2{ }^{\circ} \mathrm{C} / \mathrm{km}$ as shown in figures 4-8 of Turcotte and Schubert (1982). However, rock solidus curves are strongly dependent on hydration and mineralogy (Holland and Powell, 2001), which surely varies across the study area. At present, this limit is only needed in the Yellowstone area in and around northwestern Wyoming, where exceptionally high surface temperature gradients are observed. Further, the temperature gradient within the crust is not allowed to fall below twice this solidus gradient, which helps to ensure that the crustal and mantle geotherms converge in the upper mantle. This limit, too, applies in a very few areas and has a minimal effect on the resulting temperatures calculated for the crust.

\section{Oceans}

In the oceans, a cooling half-space model is assumed. After replacing the ratio of distance from the spreading center over spreading rate with seafloor age, $t$, in equation 4-125 of Turcotte and Schubert (1982), solving for $T(z)$ yields

$$
T(z)=\left(T_{m}-T_{S O}\right) \operatorname{erf}\left(\frac{z}{2 \sqrt{\kappa t}}\right)+T_{S O} .
$$

Here,

$T_{m} \quad$ is the temperature at the top of the convecting mantle, assumed to be $1,027^{\circ} \mathrm{C}$ (Turcotte and Schubert, 1982); and

$T_{S O} \quad$ is the temperature at the top of the oceanic crust. 
The top of the oceanic crust is taken from Boyd (2019b), which is based on the bathymetric model of Weatherall and others (2015), estimates of sediment thickness from Whittaker and others (2013), and the Juan de Fuca slab model from Hayes and others (2018). The temperature at the top of the oceanic crust is solved using equation 2 and extended through the lithospheric mantle if needed, for example, to the top of oceanic crust subducted beneath the Moho in the Pacific Northwest. Seafloor age is obtained from the study of Müller and others (2008), though in equation 10, age is corrected to account for the observation that heat flow is less than expected for crust younger than $80 \mathrm{Ma}$ and levels off for older crust (Sclater and others, 1980). This is done by setting the corrected age to $10 \mathrm{Ma}$ when the true age is zero with a linear decrease in this correction to $80 \mathrm{Ma}$ and then setting to a constant of $80 \mathrm{Ma}$ for older crust. The resulting geotherms are further modified in that the temperature gradient is not allowed to fall below $0.4^{\circ} \mathrm{C} / \mathrm{km}$, which is the value for the deeper upper mantle temperature gradient presented in appendix G3 of Stacey and Davis (2008).

\section{Surface Temperature}

Present-day surface temperature over land is taken to be an average of moderate resolution imaging spectroradiometer (MODIS) observations (Wan and others, 2015) from 2000 through 2016. This was accomplished using lower resolution, 0.1 degree, monthly averages obtained from https://neo.sci.gsfc.nasa.gov/view.php?datasetId=MOD11C1_M_LSTDA (Wan and others, 2015). Temperatures at the surface of water bodies are an inverse distance weighted average of values over land. These temperatures are attenuated through the water column to a depth $d$ according to a generic oceanic temperature profile, $T_{o}(d)$, given by

$$
T_{O}(d)=5(1-d / 6,000)^{4}+\left(T_{S}-5\right) \frac{\left(\frac{1}{2}-\operatorname{atan}(0.01 d-3) / \pi\right)^{2}}{\left(\frac{1}{2}-\operatorname{atan}(-3) / \pi\right)^{2}}
$$

and not less than the first term in this equation. This functional form is constructed and constants therein chosen to roughly match observed profiles having a strongly mixed upper layer within the top 500 meters $(\mathrm{m})$ and a more slowly varying layer below with temperatures decreasing to near $0{ }^{\circ} \mathrm{C}$ (National Oceanic and Atmospheric Administration [NOAA], 2018).

The resulting surface temperature appears in figure 1. Temperatures are generally lower at higher altitudes, higher latitudes, and at greater ocean depths. But according to research on ice cores obtained in Antarctica (Jouzel and others, 2007) and as alluded to earlier, land surface temperatures may have been more than 5 degrees cooler on average since before the start of the current interglacial maximum $10 \mathrm{ka}$ extending back more than $800 \mathrm{ka}$. A similar map is therefore generated using the process outlined above but for longer term surface temperature by decreasing land surface temperature uniformly by 5 degrees. This longer-term temperature map, which is not significantly different from that shown in figure 1 , serves as the basis for $T_{S}$ in equations $3-5$.

\section{Moho Temperature}

Moho temperatures are derived from P-wave (Pn) velocities, effectively extending the work of Schutt and others (2018) in which they estimate Moho temperatures in the WUS. Figure 2 shows a bilinear relationship between $T_{M}$ from Schutt and others (2018) and Pn velocity from Buehler and Shearer (2017), which are the underlying velocities that were used in the Schutt and others (2018) study. This bilinear relationship is used with Buehler and Shearer's (2017) complete North American Pn map to estimate $T_{M}$ outside of the WUS (fig. 3). 


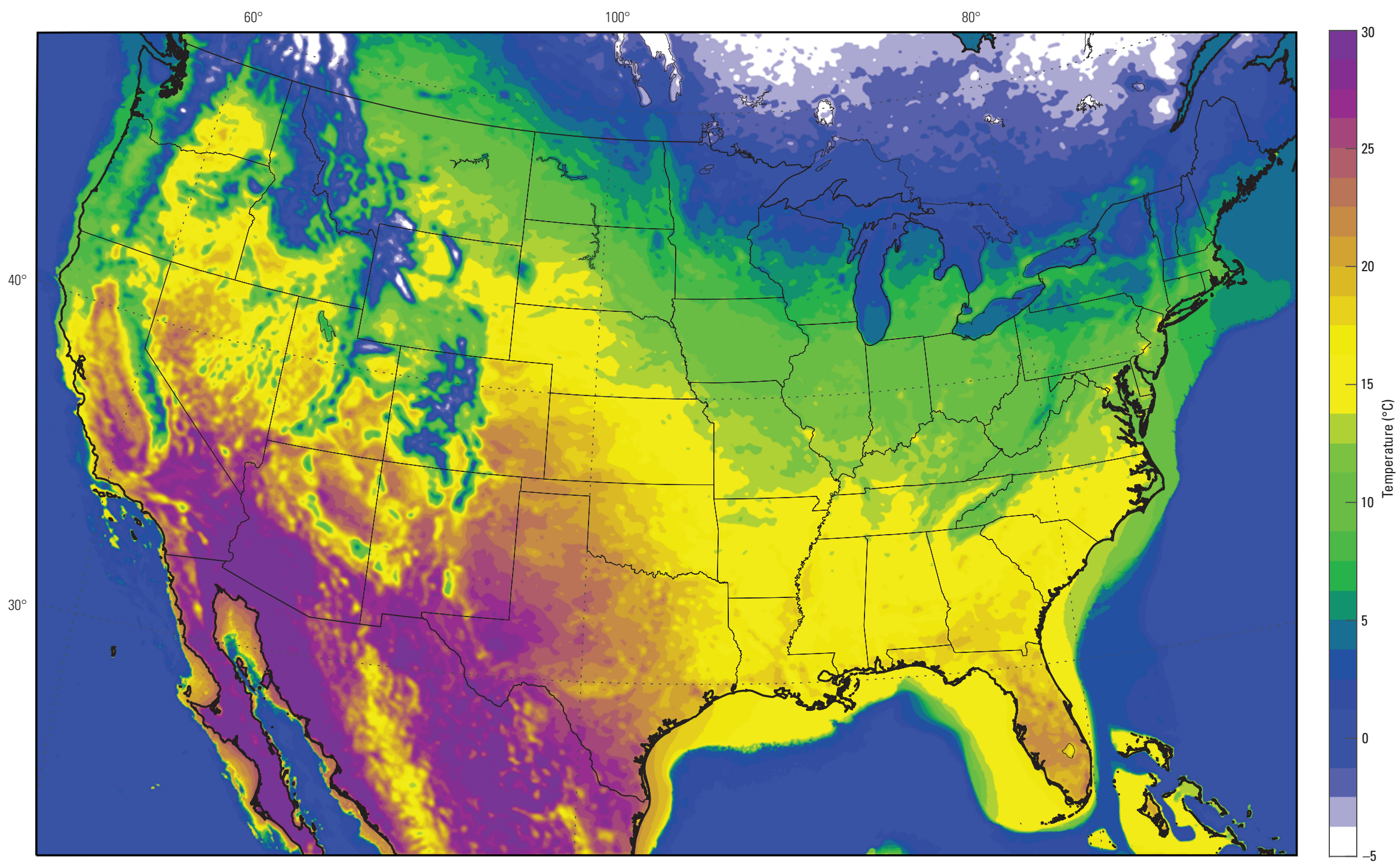

Figure 1. Present-day surface temperature in the United States and part of North America. Temperatures are generally lower at higher altitudes, higher latitudes, and at greater ocean depths. Present-day surface temperature over land is taken to be an average of moderate resolution imaging spectroradiometer (MODIS) observations (Wan and others, 2015) from 2000 through 2016. This is accomplished using lower resolution, 0.1 degree, monthly averages obtained from https://neo.sci.gsfc.nasa.gov/ view.php?datasetld=M0D11C1_M_LSTDA (Wan and others, 2015). 


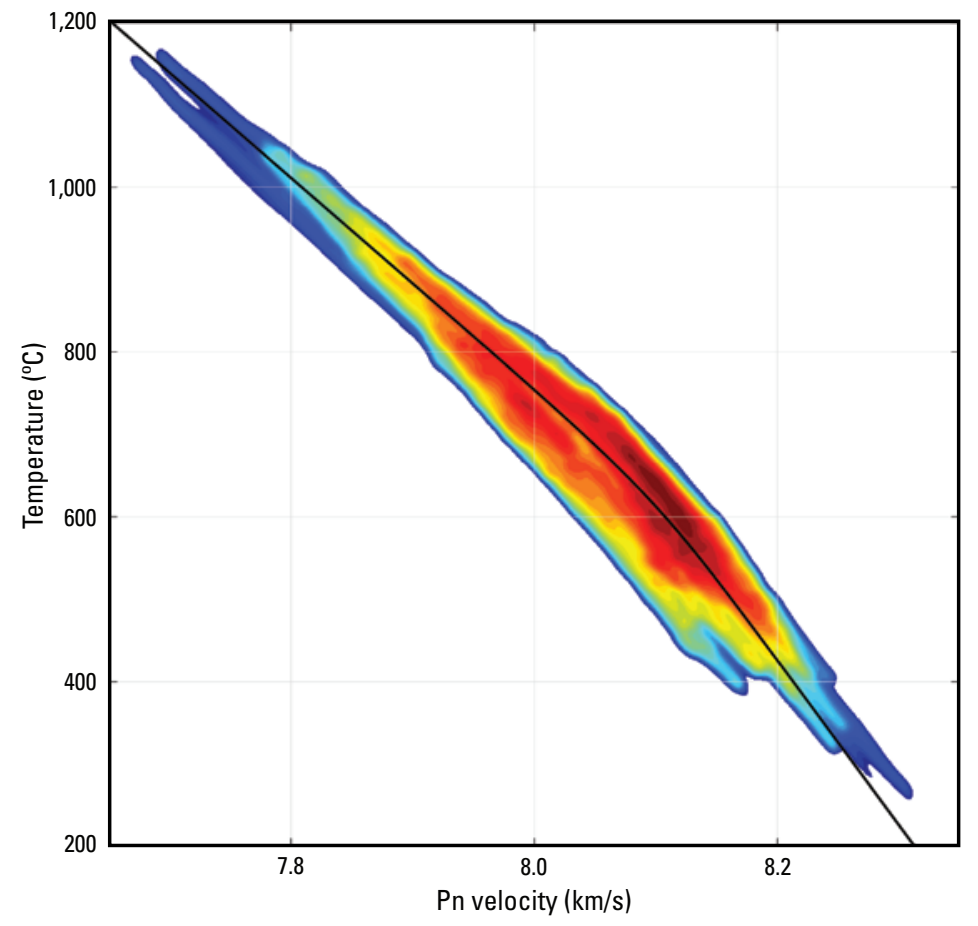

Figure 2. Graph of the bilinear relationship between P-wave (Pn) velocity (Buehler and Shearer, 2017) and Pn-based Moho temperature estimates, $T_{M^{\prime}}$ from Schutt and others (2018) in the western United States. Colors are proportional to the number of points with that value of $\mathrm{Pn}$ and Moho temperature; red, large number, blue, low number; $\mathrm{km} / \mathrm{s}$, kilometer per second; ${ }^{\circ} \mathrm{C}$, degrees Celsius.

\section{Surface Temperature Gradient and Conductivity}

Surficial temperature gradient is based primarily on the thermal database available at Southern Methodist University's Geothermal Laboratory (SMU, 2015) at http://geothermal.smu.edu/static/DatasetsZipped/core.template_heatflow_materialized.zip. Of the nearly 99,209 borehole records in and near the conterminous United States, 88,355 have corrected interval temperature gradients (fig. 4). For the roughly half of these that have interval bottom depths reported, depths range from $2 \mathrm{~m}$ to $9 \mathrm{~km}$ with a median of $1.5 \mathrm{~km}$. These gradients are assumed to be surface gradients with the understanding that small corrections could be made for depth-dependent heat production and conductivity and time-variable surface temperature.

These values are supplemented with 197 locations from the SMU database that have reported values of heat flow and conductivity but no temperature gradient, the temperature gradient being equal to heat flow divided by conductivity; 210 locations with reported heat flow and an assumed conductivity equal to the mean of the SMU dataset, $2.1 \mathrm{~W} / \mathrm{m}-\mathrm{K}$; and 9,767 temperature gradient values from a global database maintained by the University of North Dakota (UND, https://engineering.und.edu/ research/global-heat-flow-database/_files/data/global2010.xml, UND, 2015; Hasterok and Webb, 2017).

In the oceans, the surface temperature gradient is assumed to be

$$
\frac{d T}{d z_{S O}}=\frac{\left(T_{m}-T_{S O}\right)}{\sqrt{\pi \kappa t}}
$$

with parameters discussed in the "Oceans" section of this report.

The resulting surface temperature gradient appears in figure $4 A$. Gradients are higher in the WUS, particularly in areas of recent volcanism such as the Yellowstone and Crater Lake calderas and stratovolcanoes that extend from northern California up through British Columbia. Geothermal energy is being extracted from some areas with higher gradients, for example, The Geysers, Coso, and Salton Sea in California.

The conductivity surface (fig. $4 B$ ) is built from 52,023 observations of conductivity within the study area present in the SMU dataset and supplemented with an additional 98 for which heat flow and temperature gradient are reported, as well as 4,480 from the global dataset from UND. A 0.5 by 0.5 -degree grid is defined and used to fill in conductivity values where none are defined within a 0.5 -degree radius of an observation. On land, these values are an inverse average of observed values. In the oceans, conductivity is set to $1 \mathrm{~W} / \mathrm{m}-\mathrm{K}$, which is roughly the average of observed ocean values in the SMU dataset. The gridfit function in MATLAB, a modified ridge estimator written by John D'Errico, was then used with the gradient option and a level of smoothness chosen to roughly match the smoothness of the surface and Moho temperature maps. 


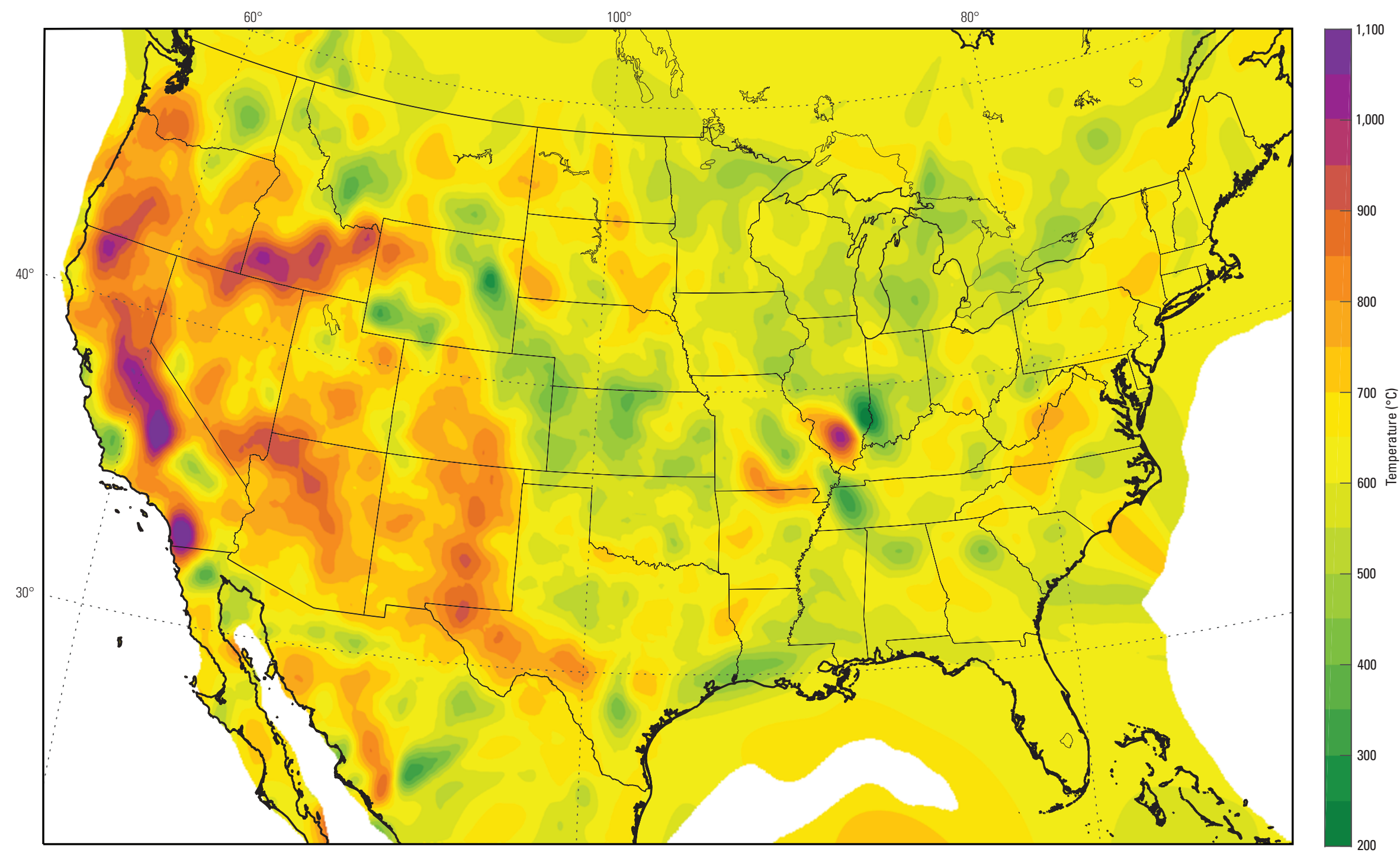

Figure 3. Map of Moho temperature in degrees Celsius $\left({ }^{\circ} \mathrm{C}\right)$ in the United States and part of North America. Moho temperatures are derived from Pn velocities, effectively extending the work of Schutt and others (2018) in which they estimate Moho temperatures in the western United States. White areas are regions of oceanic crust. 

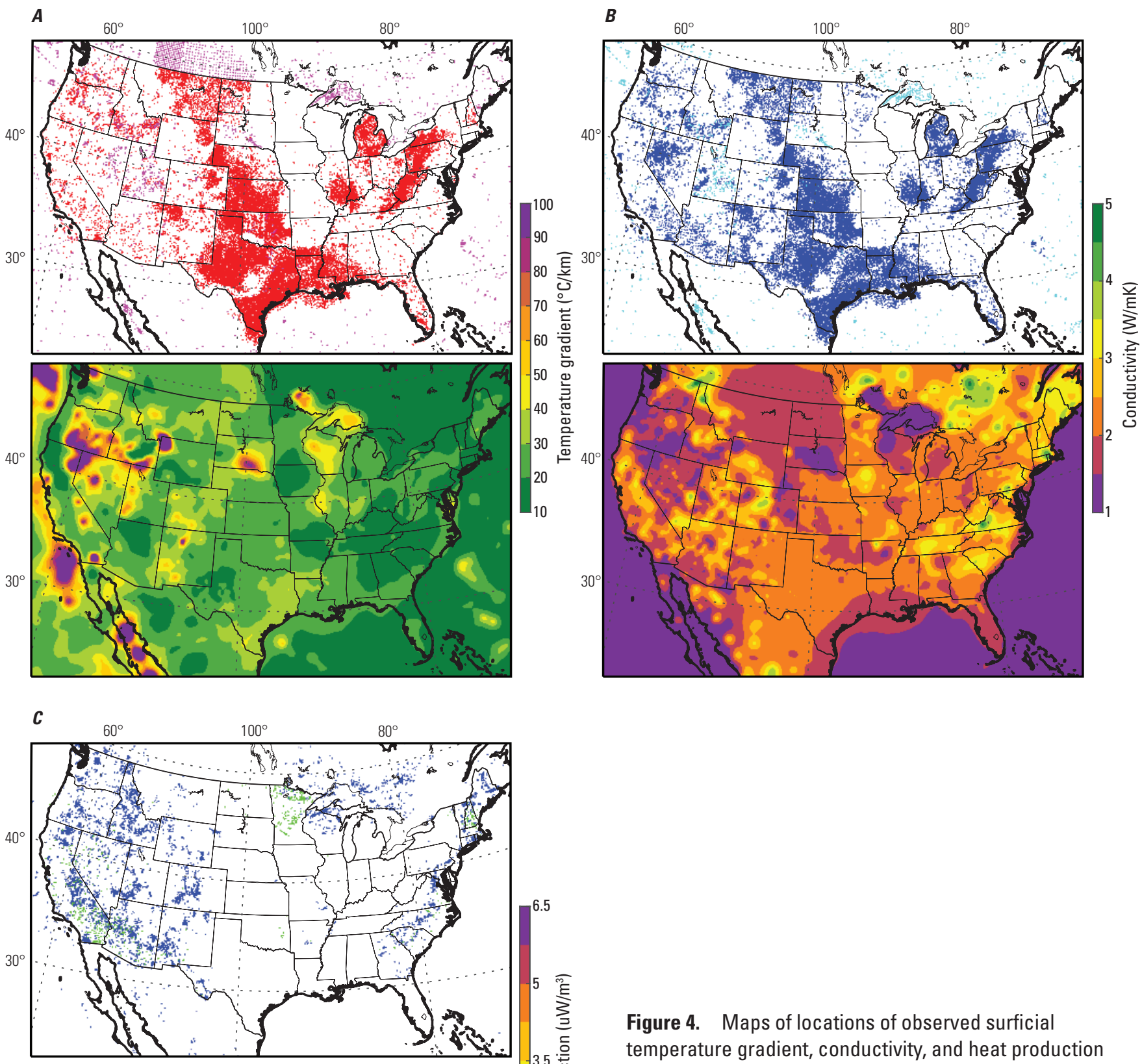

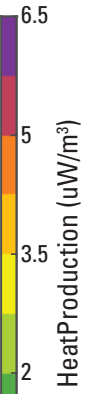

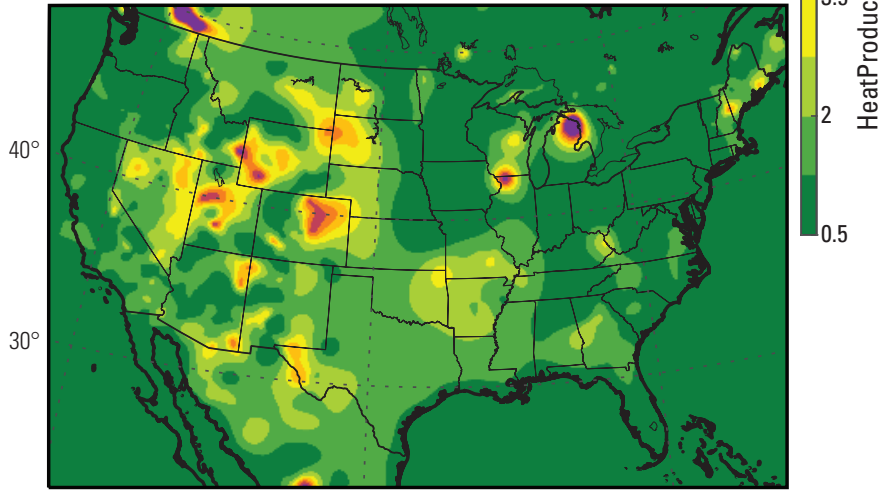

Figure 4. Maps of locations of observed surficial temperature gradient, conductivity, and heat production values in the United States and part of North America. Top panels are measured values; bottom panels are gridded surfaces. $A$, Corrected borehole temperature gradients; $B$, conductivity; and $C$, heat production, $H_{S^{*}}$ In the upper panel of $A$, red values come from the Southern Methodist University Geothermal Laboratory (SMU) database (SMU, 2015) and magenta from the global database maintained by the University of North Dakota (UND, 2015) and Hasterok and Webb (2017). In the upper panel of $B$, blue values come from the SMU database and cyan from the global database (UND). In the upper panel of $C$, green values come from the SMU database and blue from the global database (UND). 


\section{Deep Crustal Conductivity}

Figure 5 shows a comparison between predicted and observed Moho temperature for depth-independent thermal conductivity at each of the 88,762 locations where a temperature gradient is observed in the SMU dataset. In this case, the temperature gradient at each location is interpolated from the map shown in figure 4. Equations 2-4 are used where

$$
c_{3}=\frac{H_{S}}{k_{S}}
$$

and $k_{r}$ is infinite.

For this analysis, a map of surface heat production, $H_{S}$ (fig. 4), is needed and was constructed from 36,369 observations, 789 of which come from the SMU dataset and the remainder from the global dataset of Hasterok and Webb (2017). Values are assigned on a regular grid in the same manner as for conductivity, but in the oceans, a value of 0.2 microwatt per cubic meter $\left(\mathrm{mW} / \mathrm{m}^{3}\right)$ was used, the approximate average of heat production observations for oceanic basalts (Hasterok and Webb, 2017).

The assumption of depth-independent crustal conductivity yields a clear offset between predicted and observed Moho temperatures, the predicted values being roughly 50 percent higher than observed. But crustal conductivities in the SMU and global datasets are highly variable at the surface with an observed median of about $2 \mathrm{~W} / \mathrm{m}-\mathrm{K}$ and log standard deviation of 0.3 . Studies suggest that conductivity within the Earth can also be highly variable (Furlong and Chapman, 2013), decreasing with increasing temperature in the upper crust, but then increasing in the lower crust and into the mantle due to changes in composition (Hofmeister, 1999). The upper crust can be further complicated by porosity, which can significantly decrease conductivity (Clauser and Huenges, 1995).

It is therefore likely that the average crustal conductivity should increase though the crust from the average values observed in the SMU and global datasets to some larger value at the Moho. It is found that the discrepancy between observed and predicted Moho temperature can be resolved by assuming that conductivity changes exponentially with depth,

$$
k=k_{S} e^{\frac{z}{k_{r}}},
$$

having a scaling factor, $k_{r}$, given by (7) and a Moho conductivity value of $3.6 \mathrm{~W} / \mathrm{m}-\mathrm{K}$.

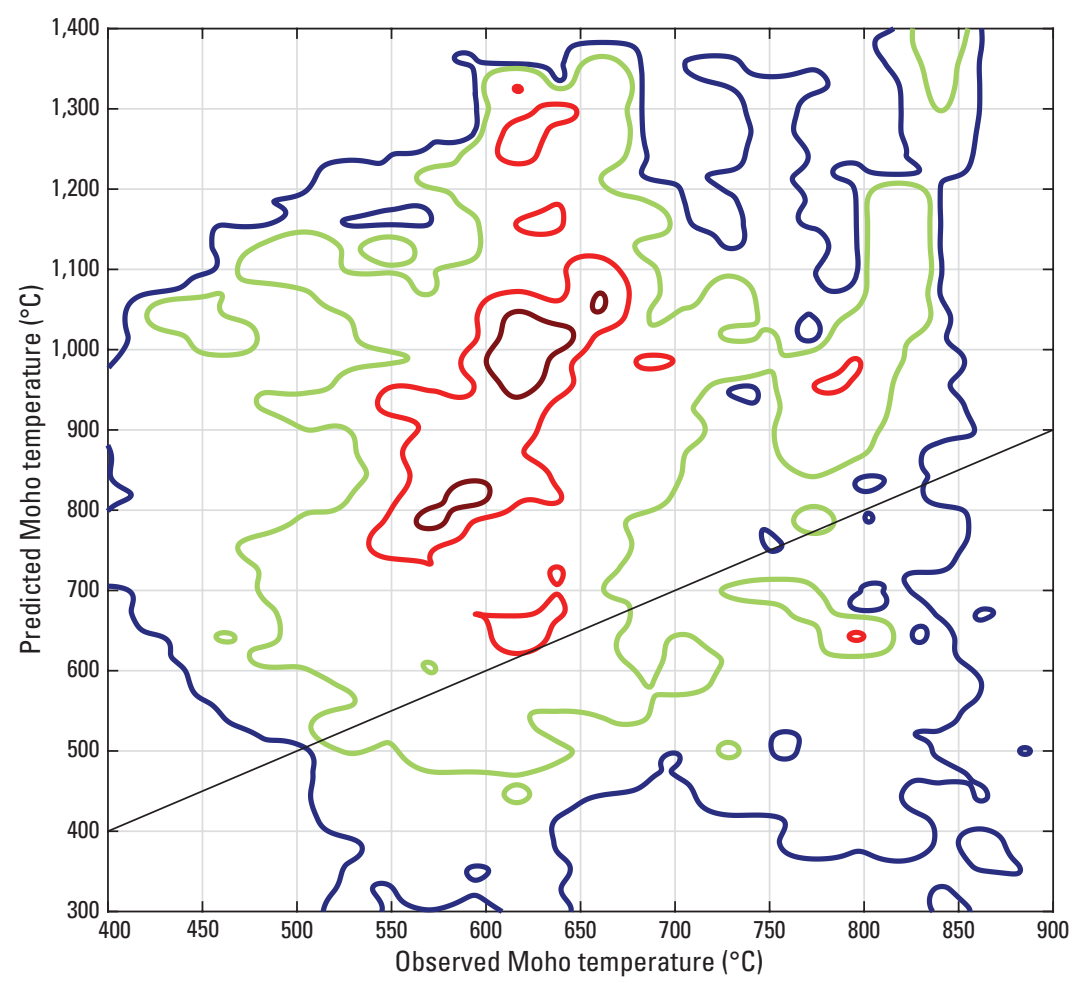

Figure 5. Graph of the comparison between observed and predicted Moho temperature for depth-independent thermal conductivity at each of the 88,762 locations where a temperature gradient is observed in the Southern Methodist University Geothermal Laboratory data set (SMU, 2015). Contours change from blue to dark red reflecting an increasing fraction of locations having those pairs of observed/predicted temperature values. The diagonal line represents a predicted value equal to the observed. ${ }^{\circ}$, degrees Celsius. 


\section{Subsurface Temperature}

With maps of surface temperature, temperature gradient, and thermal conductivity, Moho temperature, and Moho depth in hand, temperature within the model domain can be calculated. Because of exceptionally large ratios of surface temperature gradients to Moho temperature in some areas, for example, Yellowstone, and basic modeling assumptions, application of equation 2 can lead to unusual geotherms with unrealistically high temperatures within the crust and (or) negative or very low temperature gradients at the Moho. This is where the aforementioned solidus limit kicks in, which can be seen in subsequent figures. Note that application of this limit results in estimates of Moho temperatures that are greater than those presented in figure 3. Yellowstone is the only location where the temperatures in the crust actually exceed the solidus. Areas where the gradient falls below twice the solidus gradient include regions with high temperature gradients in southern Oregon and northeastern California, Long Valley caldera in central California, the Salton Sea in southern California, and Mount Baker in Washington. Other areas where the limit is applied but occur because of low Moho temperatures include northwest Colorado and southern Indiana. Overall, these limits are applied in 2 percent of the NCM map area.

Figure 6 shows temperature slices at 3.5, 10, and $30 \mathrm{~km}$ depth. In general, the temperature slowly transitions from surface temperatures to Moho temperatures modulated by crustal thickness and heat production and conductivity in the crust. Like the surface temperature gradient, temperatures are generally higher in the west in the broadly extending Basin and Range, up though the Rio Grande rift, and along the northern extension of the East Pacific Rise though California. There are also notably warmer regions in discrete areas: (1) to the east of the northern Rocky Mountains; (2) along the Gulf Coast from Mexico through southeast Texas into the Mississippi Embayment; (3) along the Appalachians; and (4) around Wisconsin.

The temperature at $3.5 \mathrm{~km}$ depth ranges from 20 to $1,100^{\circ} \mathrm{C}$ with a median of $93{ }^{\circ} \mathrm{C}$ and standard deviation of $47^{\circ} \mathrm{C}$. Moving deeper to $10 \mathrm{~km}$ depth, the minimum temperature increases by a factor of 5 to $90^{\circ} \mathrm{C}$, the maximum increases slightly to $1,120^{\circ} \mathrm{C}$, the median increases to $227^{\circ} \mathrm{C}$, and the standard deviation doubles to $79^{\circ} \mathrm{C}$. Within California, temperatures at $3.5 \mathrm{~km}$ depth range from 60 to $747^{\circ} \mathrm{C}$ with a median of $123^{\circ} \mathrm{C}$ and standard deviation of $58^{\circ} \mathrm{C}$. At $10 \mathrm{~km}$ depth, the range increases to between 211 and $964^{\circ} \mathrm{C}$ with a median of $317^{\circ} \mathrm{C}$ and standard deviation of $82^{\circ} \mathrm{C}$.

These results are broadly consistent with the proprietary temperature maps produced by Blackwell and others (2011) and figure 6, with notable differences. The work presented here results in greater temperatures in the WUS, which may be partially due to the use of a Moho temperature map, which was not used in the SMU model. However, the SMU model appears to have more detailed structure, which is likely due to their inclusion of geologic constraints.

In figure 7, 1D profiles at four locations as indicated in figure 6 are presented. Two of the locations are in the older and colder region of the CEUS and the other two are in the younger and warmer region of the WUS. Profile $C$ is in Yellowstone. Temperatures at this location increase quickly and are limited by the solidus gradient to about $1,100{ }^{\circ} \mathrm{C}$ near $6 \mathrm{~km}$ depth.

Differences between oceanic and continental geotherms can also lead to large lateral variability, though generally at greater depth. This is seen in the panel $D$ of figure 6 and in figure 8 moving from west to east through Washington where temperatures within the oceanic plate are relatively steady but then increase dramatically and then fluctuate more rapidly within and beneath the continental crust. 

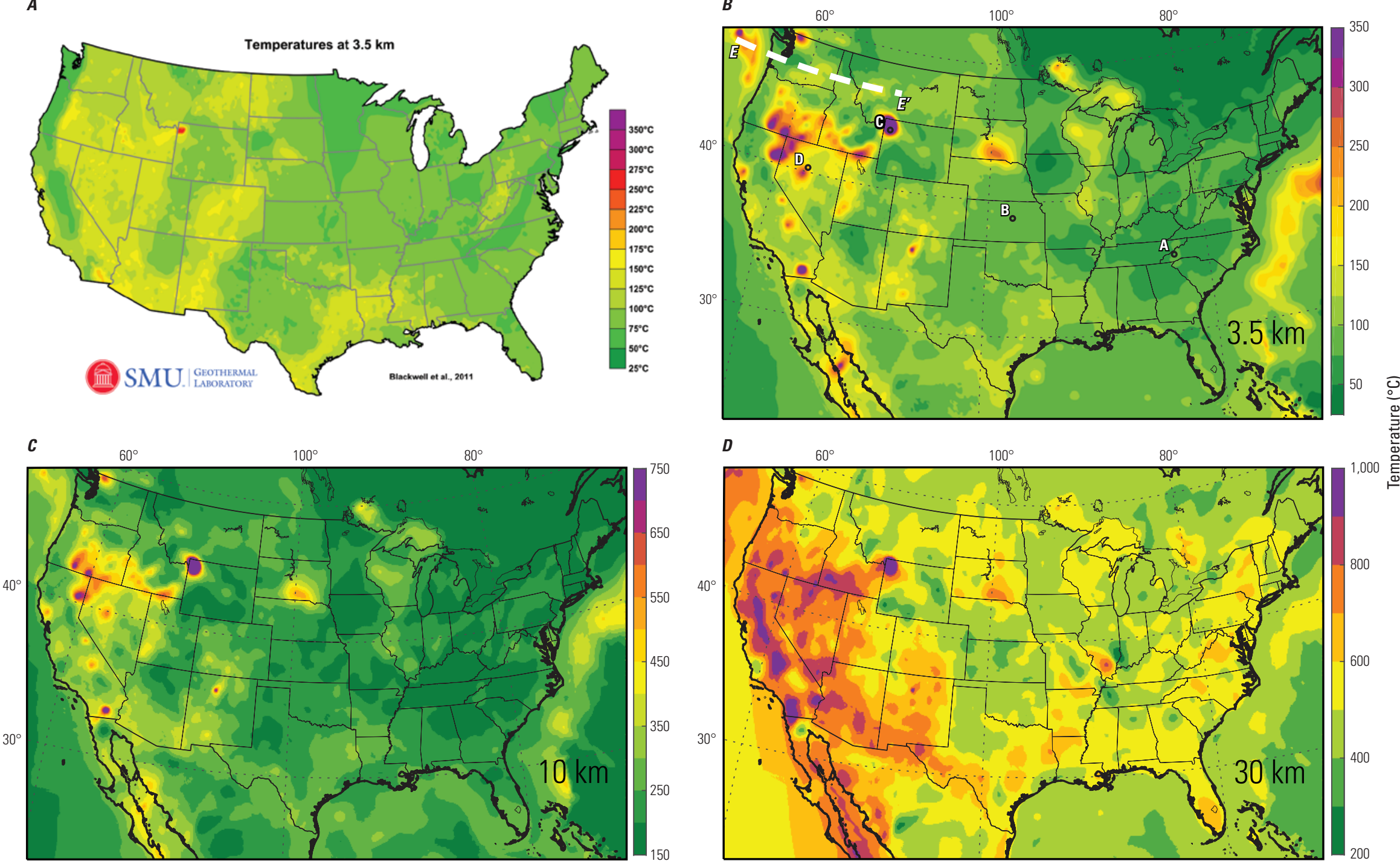

Figure 6. Maps of temperature slices within the U.S. Geological Survey National Crustal Model domain at $3.5(B), 10(C)$, and $30(D)$ kilometers $(\mathrm{km})$ depth as well as the temperature at $3.5 \mathrm{~km}$ depth from the Southern Methodist Geothermal Laboratory (SMU, 2015) model (A). In general, the temperature slowly transitions from surface temperatures to Moho temperatures modulated by crustal thickness and heat production and conductivity in the crust. Like the surface temperature gradient, temperatures are generally higher in the west in the broadly extending Basin and Range, up though the Rio Grande rift, and along the northern extension of the East Pacific Rise though California. In panel $B$, locations of profiles appearing in figures 7 and 8 are indicated. ${ }^{\circ} \mathrm{C}$, degrees Celsius. 


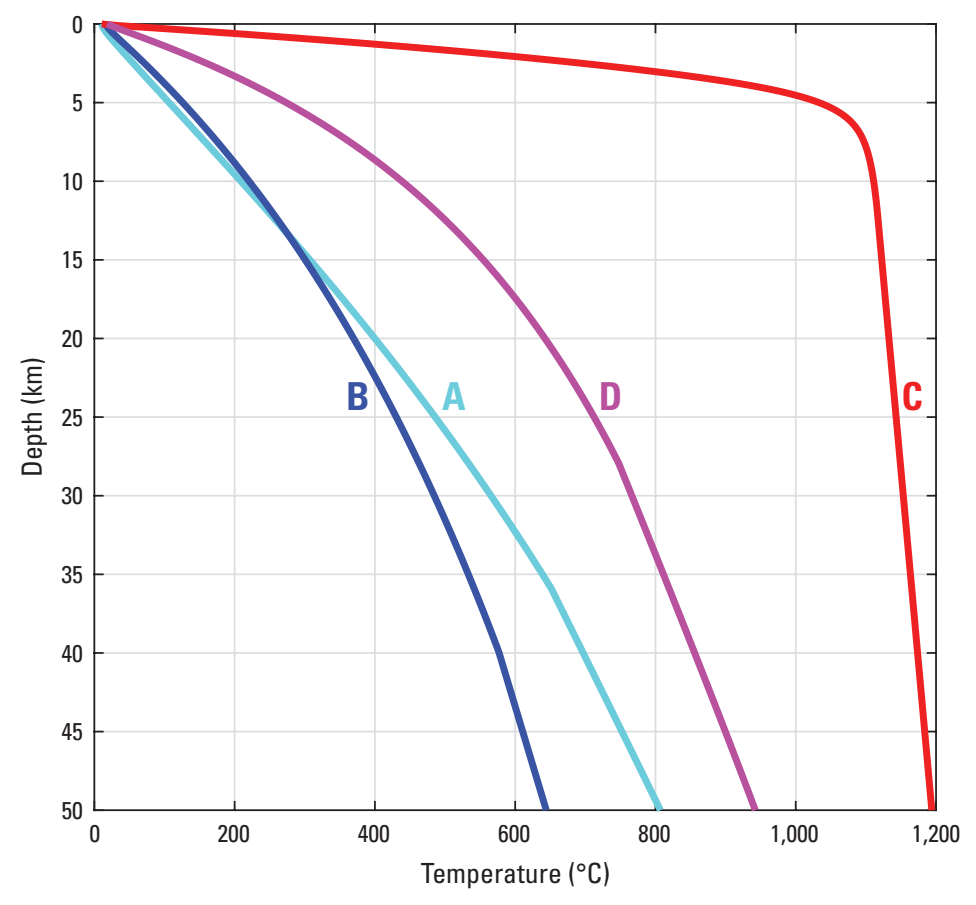

Figure 7. One-dimensional temperature profiles at four locations across the United States with locations indicated in figure $6 B$. Locations $A$ and $B$ are in the older and colder region of the central and eastern United States (CEUS), and $\mathrm{C}$ and $\mathrm{D}$ are in the younger and warmer region of the western United States (WUS). Location C is in the Yellowstone area and illustrates the high surface temperature gradient and the need to apply the solidus limit (the strong change in slope at about 6 kilometers $[\mathrm{km}]$ depth). ${ }^{\circ}$, degrees Celsius.

\section{Discussion}

The analysis presented in this report was carried out to better account for the effects of temperature on density, modulus, and attenuation in the NCM as compared to using a constant temperature gradient. Significant lateral temperature variability is present and increases with depth. According to mineral physics calculations using the database and methods outlined in Sowers and Boyd (2019), density contrasts due to variations in temperature for a given rock type at any given depth within the crust are likely to be less than $\sim 3$ percent. Anelastic P-wave and S-wave velocity contrasts are also likely to be relatively small, less than 10 percent. But the effect of temperature on seismic attenuation and the resulting velocity dispersion may be considerable with a greater effect on $\mathrm{S}$-wave velocity than $\mathrm{P}$-wave velocity. Furthermore, the phase transition from $\alpha$ to $\beta$ quartz, a mineral which is present in significant quantities in many rocks and the transition of which causes significant changes to modulus and density, is sensitive to temperature, decreasing in depth with increasing temperature (Shen and others, 1993).

Two important limitations to this analysis are that depth-dependent variations in density are not considered, and depthdependent variations in heat production and conductivity are specified in a very basic way. These properties depend on the geology (including the presence of hydrous phases and melt), porosity, pressure, and temperature, thereby creating a highly nonlinear problem. Furthermore, the work presented here is essentially a static 1D analysis. Significant effort would be required to solve this problem to more than $50 \mathrm{~km}$ depth with 3D time-dependent numerical methods. Application of a 3D geologic model with 3D numerical methods would result in a more accurate model but one that might not be substantially different than the simpler model presented here, at least for the purposes of estimating seismic velocity and earthquake ground motions.

\section{Conclusions}

This report details the construction of a temperature model to be used in support of the USGS National Crustal Model and calculations of mineral moduli and density and seismic attenuation. The model is defined by surface temperature, temperature gradient, and conductivity, Moho temperature and depth, the top of the oceanic plate, and equations for steady-state heat conduction in the continental crust and cooling of a half-space in ocean crust. Thermal conductivity at the Moho is found to be 3.6 watts per meter-Kelvin in order to match average predicted and inferred Moho temperatures. Temperature variations are modest at the surface with differences on the order of 30 degrees, and temperatures throughout the crust increase to the southwest. With increasing depth, differences in temperature increase markedly, reaching 900 degrees Celsius or more at the Moho. 


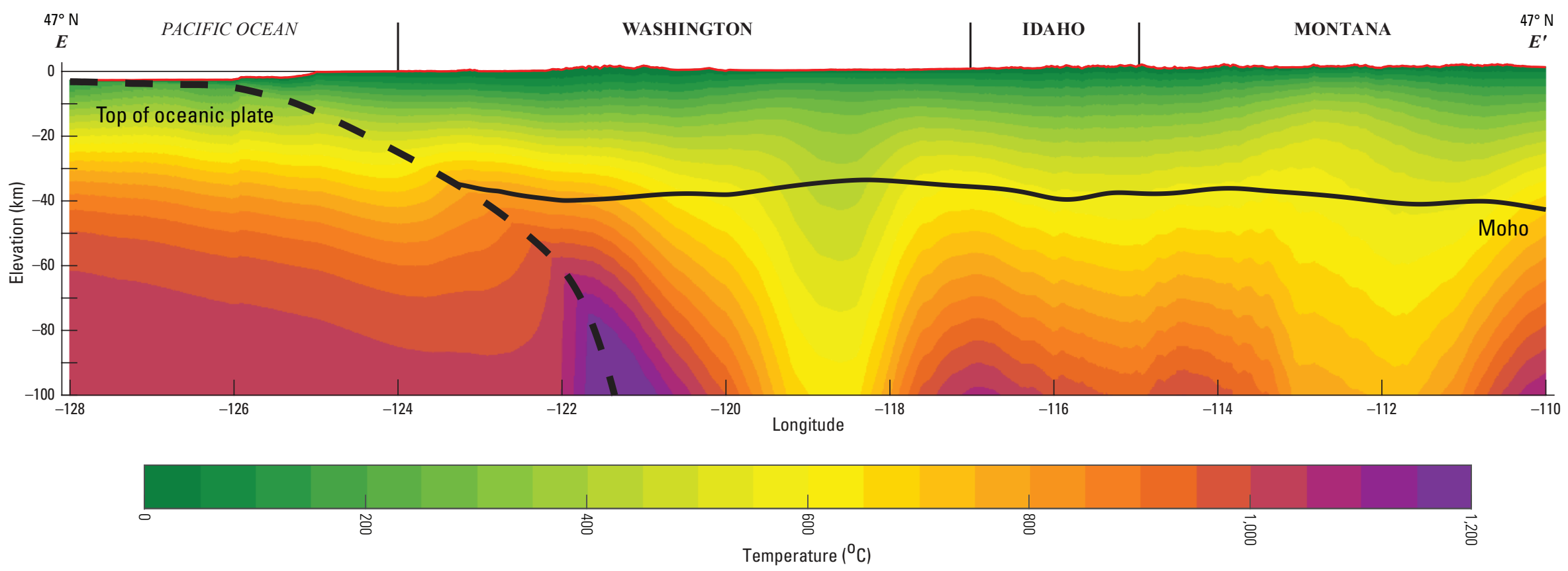

Figure 8. Cross section of a temperature profile through the Cascadia subduction zone in Washington, Idaho, and part of Montana. Location of profile is indicated in figure $6 B$, white dashed line $E-E^{\prime}$. Solid line is the Moho and dashed line is the top of the subducting slab. 


\section{Acknowledgments}

I am grateful to Wayne Thatcher and Yuehua Zeng of the U.S. Geological Survey for providing thoughtful reviews that stimulated discussion and resulted in substantial improvements to this work. This effort was funded by the U.S. Geological Survey Earthquake Hazards Program.

\section{References Cited}

Blackwell, D., Richards, M., Frone, Z., Batir, J., Ruzo, A., Dingwall, R., and Williams, M., 2011, Temperature-at-depth maps for the conterminous U.S. and geothermal resource estimates: Geothermal Research Council Transactions, v. 35, p. 1545-1550. [Also available at http://pubs.geothermal-library.org/lib/grc/1029452.pdf.]

Boyd, O.S., 2019a, Grids in support of the U.S. Geological Survey thermal model for seismic hazard studies: U.S. Geological Survey data release, https://doi.org/10.5066/P935DT1G.

Boyd, O.S., 2019b, 3D geologic framework for use with the USGS National Crustal Model, Phase 1-Western United States: U.S. Geological Survey Open-File Report, v. 2019-1081, 36 p., https://doi.org/10.3133/ofr20191081.

Boyd, O.S. and Shah, A.K., 2018, Layers of the USGS National Crustal Model: U.S. Geological Survey data release, accessed September 27, 2018, at https://doi.org/10.5066/P9T96Q67.

Buehler, J.S., and Shearer, P.M., 2017, Uppermost mantle seismic velocity structure beneath USArray: Journal of Geophysical Research, v. 122, p. 436-448, accessed October 28, 2018, at https://ds.iris.edu/ds/products/emc-pnus_2016/.

Čermák, V., and Bodri, L., 1992, Crustal thinning during rifting-A possible signature in radiogenic heat production: Tectonophysics, v. 209, p. 227-239. [Also available at https://doi.org/10.1016/0040-1951(92)90027-4.]

Clauser, C., and Huenges, E., 1995, Thermal conductivity of rocks and minerals, in Ahrens, T.J., ed., Rock physics and phase relations, A handbook of physical constants: Washington, D.C., American Geophysical Union, p. 105-126.

Furlong, K.P., and Chapman, D.S., 2013, Heat flow, heat generation, and the thermal state of the lithosphere: Annual Review of Earth and Planetary Sciences, v. 41, p. 385-410, accessed March 14, 2019, at https://www.annualreviews.org/doi/10.1146/ annurev.earth.031208.100051.

Hasterok, D., and Webb, J., 2017, On the radiogenic heat production of igneous rocks: Geoscience Frontiers, v. 8, p. 919-940, accessed March 7, 2019, at https://doi.org/10.1016/j.gsf.2017.03.006.

Hayes, G.P., Moore, G.L., Portner, D.E., Hearne, M., Flamme, H., Furtney, M., and Smoczyk, G.M., 2018, Slab2, a comprehensive subduction zone geometry model: Science, v. 362, no. 6410, p. 58-61, accessed August 15, 2018, at https://doi.org/10.1126/science.aat4723.

Hofmeister, A.M., 1999, Mantle values of thermal conductivity and the geotherm from phonon lifetimes: Science, v. 283, no. 5408, p. 1699-1706. [Also available at https://doi.org/10.1126/science.283.5408.1699.]

Holland, T., and Powell, R., 2001, Calculation of phase relations involving haplogranitic melts using an internally consistent thermodynamic dataset: Journal of Petrology, v. 42, no. 2, p. 673-683. [Also available at https://doi.org/10.1093/petrology/42.4.673.]

Jouzel, J., Masson-Delmotte, V., Cattani, O., Dreyfus, G., Falourd, S., Hoffmann, G., Minster, B., Nouet, J., Barnola, J.M., Chappellaz, J., Fischer, H., Gallet, J.C., Johnsen, S., Leuenberger, M., Loulergue, L., Luethi, D., Oerter, H., Parrenin, F., Raisbeck, G., Raynaud, D., Schilt, A., Schwander, J., Selmo, E., Souchez, R., Spahni, R., Stauffer, B., Steffensen, J.P., Stenni, B., Stocker, T.F., Tison, J.L., Werner, M., and Wolff, E.W., 2007, Orbital and millennial Antarctic climate variability over the past 800,000 years: Science, v. 317, no. 5839, p. 793-797. [Also available at https://doi.org/10.1126/science.1141038.]

Kaban, M.K., M. Tesauro, Mooney, W.D., and Cloetingh, S.A.P.L., 2014, Density, temperature, and composition of the North American lithosphere-New insights from a joint analysis of seismic, gravity, and mineral physics data - 1 . Density structure of the crust and upper mantle: Geochemistry, Geophysics, Geosystems, v. 15, p. 4781-4807, accessed February 5, 2015, at https://doi.org/10.1002/2014GC005483. 
Müller, R.D., Sdrolias, M., Gaina, C., and Roest, W.R., 2008, Age, spreading rates, and spreading asymmetry of the world's ocean crust: Geochemistry, Geophysics, Geosystems, v. 9, no. 4., 19 p. [Also available at https://doi.org/10.1029/2007GC001743.]

National Oceanic and Atmospheric Administration (NOAA), 2018, What is a thermocline?: National Oceanic and Atmospheric Administration, National Ocean Service website, accessed July 25, 2018, at https://oceanservice.noaa.gov/facts/thermocline.html.

Pasyanos, M.E., Masters, T.G., Laske, G., and Ma, Z., 2014, LITHO1.0_-An updated crust and lithospheric model of the Earth: Journal of Geophysical Research, v. 119, no. 3, p. 2153-2173, accessed August 22, 2017, at https://doi.org/10.1002/2013JB010626.

Schutt, D.L., Lowry, A.R., and Buehler, J.S., 2018, Moho temperature and mobility of lower crust in the western United States: Geology, v. 46, no. 3, p. 219-222, accessed May 22, 2018, at https://doi.org/10.1130/G39507.1.

Sclater, J.G., Jaupart, J., and Galson, D., 1980, The heat flow through oceanic and continental crust and the heat loss of the Earth: Reviews of Geophysics and Space Physics, v. 18, p. 269-311. [Also available at https://doi.org/10.1029/ RG018i001p00269.]

Shen, A.H., Bassett, W.A., and Chou, I.-M., 1993, The $\alpha-\beta$ quartz transition at high temperatures and pressures in a diamondanvil cell by laser interferometry: American Mineralogist, v. 78, p. 694-698. [Also available at https://pubs.geoscienceworld. org/msa/ammin/article/78/7-8/694/42768/the-quartz-transition-at-high-temperatures-and.]

Southern Methodist University Geothermal laboratory (SMU), 2015, National geothermal data system (NGDS), geothermal aggregation: Dallas, Tex., Southern Methodist University Geothermal Laboratory, accessed July 24, 2018, at http://geothermal.smu.edu/gtda/.

Sowers, T., and Boyd, O.S., 2019, Petrologic and mineral physics database for use with the U.S. Geological Survey National Crustal Model: U.S. Geological Survey Open-File Report 2019-1035, 17 p., https://doi.org/10.3133/ofr20191035.

Stacey, F., 1992, Physics of the Earth (3d ed.): Queensland, Australia, Brookfield Press, 513 p.

Stacey, F., and Davis, P.M., 2008, Physics of the Earth (4th ed.): New York, Cambridge University Press, 548 p.

Turcotte, D.L., and Schubert, G., 1982, Geodynamics: New York, John Wiley \& Sons, 450 p.

University of North Dakota (UND), 2015, Global heat flow database: Grand Forks, N. Dak., University of North Dakota, College of Engineering and Mines, accessed March 7, 2019, at https://engineering.und.edu/research/global-heat-flow-database/.

Wan, Z., Hook, S., and Hulley, G., 2015, MOD11C1 MODIS/Terra land surface temperature/emissivity daily L3 global 0.05deg CMG V006 [data set]: NASA EOSDIS Land Processes DAAC, accessed July 25, 2018, https://neo.sci.gsfc.nasa.gov/view. php?datasetId=MOD11C1_M_LSTDA.

Weatherall, P., Marks, K.M., Jakobsson, M., Schmitt, T., Tani, S., Arndt, J.E., Rovere, M., Chayes, D., Ferrini, V., and Wigley, R., 2015, A new digital bathymetric model of the world's oceans: Earth and Space Science, v. 2, p. 331-345, accessed April 19, 2018, at https://doi.org/10.1002/2015EA000107.

Whittaker, J., Goncharov, A., Williams, S., Müller, R.D., and Leitchenkov, G., 2013, Global sediment thickness dataset updated for the Australian-Antarctic Southern Ocean: Geochemistry, Geophysics, Geosystems, v. 14, no. 8, p. 3297-3305, accessed January 5, 2017, at https://doi.org/10.1002/ggge.20181. 


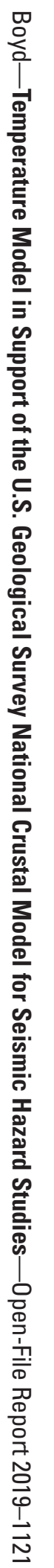

